\title{
Use of the bolus tracking technique for the tomographic evaluation of the uretero-vesicular junction in dogs and assessment of dose records
}

\author{
Maurizio Longo ${ }^{1 *}$, Maria Elena Andreis ${ }^{1}$, Cinzia Pettinato ${ }^{2}$, Giuliano Ravasio ${ }^{1}$, Vanessa Rabbogliatti ${ }^{1}$,
} Donatella De Zani ${ }^{1}$, Mauro Di Giancamillo ${ }^{1}$ and Davide Danilo Zani ${ }^{1}$

\begin{abstract}
Background: The aim of the work is the application of a bolus tracking technique for tomographic evaluation of the uretero-vesicular junction in dogs. Ten adult dogs (8-14 years) with variable body weight $(2,8-32 \mathrm{~kg})$ were enrolled in the prospective study. The patients were placed in sternal recumbency with a $10^{\circ}$ elevated pelvis and the visualization of the uretero-vesicular junction was obtained with the bolus tracking technique after intravenous administration of non-ionic contrast medium. In the post-contrast late phase a region of interest was placed within the lumen of the distal ureters and the density values were monitored before starting the helical scan.

Results: The uretero-vesicular junction was clearly visible in $100 \%$ of patients with the visualization of the endoluminal ureteral contrast enhancement and bladder washout. At the end of the tomographic study an evaluation of the dose records was performed and compared to human exposures reported in literature for the pelvic region. The effective dose estimated for each patient (37,5-138 mSv) proved to be elevated, when compared to those reported in human patients.

Conclusion: The bolus tracking technique could be applied for the visualization of the uretero-vesicular junction in non-pathological patients, placing the region of interest in the distal ureters. The high effective doses recorded in our study support the need of specific thresholds for veterinary patients, pointing out the attention for paediatric patient's exposure also in veterinary imaging.
\end{abstract}

Keywords: uro-CT, uretero-vesicular junction, bolus tracking, DLP, CTDI, ureter

\section{Background}

Ureteral ectopia is a pathological condition that occurs as a result of abnormal caudal migration of the ureteral bud at the level of its insertion to the urinary bladder [1]. This pathological condition, widely represented both in humans and animals, can lead to severe mechanical obstruction with consequent hydroureter, hydronephrosis and pyelectasis in chronic and more severe stages of the disease. Computed tomography has been considered the modality of choice for the evaluation of the pelvic

\footnotetext{
* Correspondence: maurizio.longo@unimi.it

${ }^{1}$ Department of Veterinary Medicine (DIMEVET), Università degli Studi di Milano, Ospedale Didattico Universitario Az. Polo Veterinario di Lodi, Via dell'Università 6, 26900 Lodi, LO, Italy

Full list of author information is available at the end of the article
}

region, avoiding superimposition of structures, limited contrast and spatial resolution. Computed tomography Excretory Urography (CTEU), dynamic scans of the pelvic region, has been reported [2-8] as a useful tool to evaluate the distal ureteral jet of the contrast media. Moreover, the administration of complementary drugs, such as furosemide, or different patients positioning, supine vs sternal, for the optimization of the visualization of the distal portion of the ureters has been well investigated [7-12].

Because of the difficulty to correctly visualise the uretero-vesicular junction, very often many repeated helical CT scans of the pelvic region are required, strongly increasing patient exposure. In order to achieve qualitative 
images of the uretero-vesicular junction, optimizing scanning time delay is mandatory, although it could be widely different among patients $[7,8]$.

The aim of this work was to evaluate the feasibility to use the bolus tracking technique to visualize the uretero-vesicular junction in dogs. Additionally, an estimation of the exposure parameters was performed.

\section{Methods}

Dogs referred to our Institution for neoplasms staging and without signs of urinary tract illness have been enrolled in the prospective study. Premedication was not standardized. In all dogs, anaesthesia was induced with propofol and maintained by isoflurane in oxygen $100 \%$ (Table 1).

Images were acquired using a 16-slices $\mathrm{CT}$ scanner (GE Brightspeed ${ }^{\circ}$, GE Healthcare Milano - Italy). Dogs were examined in sternal recumbency with the pelvis elevated on a wedge with a $5^{\circ}$ to $10^{\circ}$ angle [13]. CT acquisition parameters, according to patient dimensions, were set as follows: $120 \mathrm{kV}, 150-200 \mathrm{~mA}, 1,25 \mathrm{~mm}$ thick contiguous slices.

For contrast enhanced CT images, a bolus injection of a non-ionic iodinated contrast medium, Ioexhol (Omnipaque $350 \mathrm{mg} / \mathrm{ml}$, GE Healthcare Milano - Italy) was administered into the cephalic vein via 18-27 G catheter at a dose of $600 \mathrm{mgI} / \mathrm{kg}$, using a pressure injector $\left(\right.$ Medrad $^{\circ}$ Mark V Plus, Milano Italy) and a rate of $2-3 \mathrm{ml} / \mathrm{s}$.

The acquisition protocol was as follows: 1) total body CT scan; 2) contrast enhanced total body CT scan; 3 ) post contrast late phase limited to the abdomen, using the bolus tracking on the ureters.

Contrast medium was injected into the patient and a ROI was positioned on the distal third of the ureteral lumen, cranial to the caudo-medial deflection, in order to track the volume of contrast (Fig. 1). CT images were acquired, according to literature, after the $150 \mathrm{HU}$ level

Table 1 Breed, Weight, Age, Sex, CT indication and Anaesthetic Protocols

\begin{tabular}{|c|c|c|c|c|c|}
\hline Breed & Weight (kg) & Age (years) & Sex & CT indication & Anaesthetic protocol \\
\hline Akita & 30 & 13 & NF & rectal neoplasm & $\begin{array}{l}\text { I: dex } 3 \mu \mathrm{g} / \mathrm{kg} \text { e.v. }+ \text { ppf } \sim 2,5 \mathrm{mg} / \mathrm{kg} \text { e.v. } \\
\text { M: iso in oxygen } 100 \%\end{array}$ \\
\hline Pinscher & 6 & 14 & $\mathrm{IM}$ & bone neoplasm & $\begin{array}{l}\text { I: dex } 3 \mu \mathrm{g} / \mathrm{kg} \text { e.v. }+ \text { ppf } \sim 2,5 \mathrm{mg} / \mathrm{kg} \text { e.v } \\
\text { M: iso in oxygen } 100 \%\end{array}$ \\
\hline Mixed breed & 5,5 & 8 & $\mathrm{IM}$ & suspected hepatic neoplasm & $\begin{array}{l}\text { I: dex } 3 \mu \mathrm{g} / \mathrm{kg} \text { e.v. }+ \text { ppf } \sim 2,5 \mathrm{mg} / \mathrm{kg} \text { e.v. } \\
\text { M: iso in oxygen } 100 \%\end{array}$ \\
\hline Irish Setter & 26 & 8 & NF & mammary neoplasm & $\begin{array}{l}\text { I: dex } 3 \mu \mathrm{g} / \mathrm{kg} \text { e.v. }+ \text { ppf } \sim 2,5 \mathrm{mg} / \mathrm{kg} \text { e.v } \\
\text { M: iso in oxygen } 100 \%\end{array}$ \\
\hline Labrador Retriever & 32 & 10 & NF & hepatic/splenic neoplasm & $\begin{array}{l}\text { P: dex } 1 \mu \mathrm{g} / \mathrm{kg} \text { e.v }+ \text { but } 0,2 \mathrm{mg} / \mathrm{kg} \text { e.v. } \\
\text { I: ppf e.v. to effect }(\sim 4 \mathrm{mg} / \mathrm{kg}) \\
\text { M: iso in oxygen } 100 \%\end{array}$ \\
\hline Pinscher & 5 & 8 & IF & mammary neoplasm & $\begin{array}{l}\text { P: dex } 5 \mu \mathrm{g} / \mathrm{kg} \text { i.m. }+ \text { met } 0,2 \mathrm{mg} / \mathrm{kg} \text { i.m. } \\
\text { I: ppf } \sim 2,5 \mathrm{mg} / \mathrm{kg} \text { e.v } \\
\text { M: iso in oxygen } 100 \%\end{array}$ \\
\hline Mixed breed & 30 & 11 & IF & mammary neoplasm & $\begin{array}{l}\text { P: dex } 5 \mu \mathrm{g} / \mathrm{kg} \text { i.m. }+ \text { met } 0,2 \mathrm{mg} / \mathrm{kg} \text { i.m. } \\
\text { I: ppf e.v. to effect }(\sim 4 \mathrm{mg} / \mathrm{kg}) \\
\text { M: iso in oxygen } 100 \%\end{array}$ \\
\hline Pinscher & 2,8 & 8 & IF & mammary neoplasm & $\begin{array}{l}\text { P: dex } 10 \mu \mathrm{g} / \mathrm{kg} \text { i.m. }+ \text { but } 0,2 \mathrm{mg} / \mathrm{kg} \text { i.m. } \\
\text { I: ppf e.v. to effect }(\sim 4 \mathrm{mg} / \mathrm{kg}) \\
\text { M: iso in oxygen } 100 \%\end{array}$ \\
\hline Pug & 11 & 12 & $\mathrm{IM}$ & mandibular neoplasm & $\begin{array}{l}\text { P: but } 0,2 \mathrm{mg} / \mathrm{kg} \text { e.v. } \\
\text { I: ppf e.v. to effect }(\sim 4 \mathrm{mg} / \mathrm{kg}) \\
\text { M: iso in oxygen } 100 \%\end{array}$ \\
\hline English Setter & 20 & 10 & IF & mammary neoplasm & $\begin{array}{l}\text { P: dex } 5 \mu \mathrm{g} / \mathrm{kg} \text { i.m. }+ \text { met } 0,2 \mathrm{mg} / \mathrm{kg} \text { i.m. } \\
\text { I: ppf e.v. to effect }(\sim 4 \mathrm{mg} / \mathrm{kg}) \\
\text { M: iso in oxygen } 100 \%\end{array}$ \\
\hline
\end{tabular}




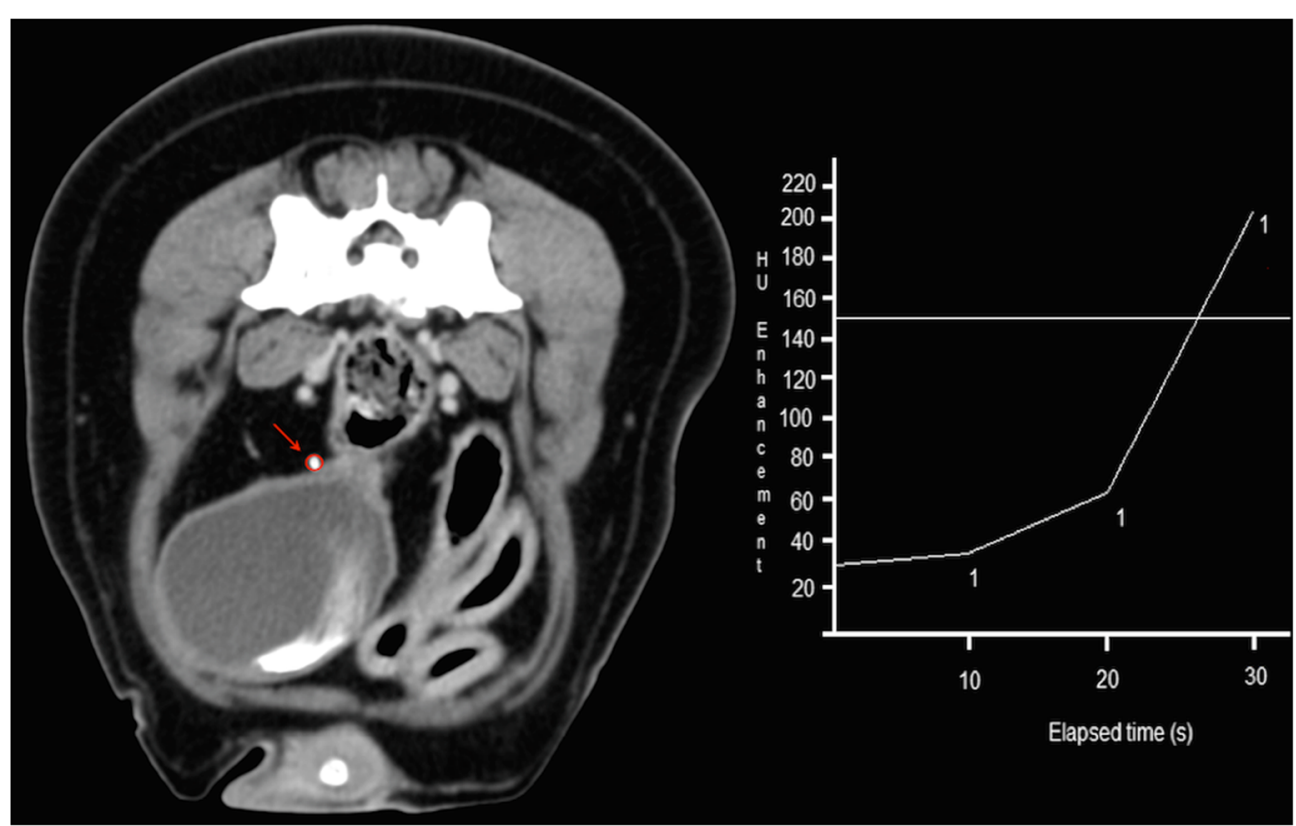

Fig. 1 Transverse image at the level of the distal third of the right ureteral lumen, cranial to the caudo-medial deflection. Positioning of the ROI (red arrow and circle) and tracking of the progressive intraluminal peak enhancement (HU enhancement/elapsed time diagram)

was reached into the ROI [14]. During the monitoring phase, low exposure $(50 \mathrm{~mA})$ repeated axial scans were performed at the pre-selected level (Fig. 1). By means of a built-in software program a near instantaneous time attenuation curve was generated. When contrast medium reached the desired $150 \mathrm{HU}$ (Fig. 1) the operator triggered a complete helical scan of the caudal abdomen.

Lactated Ringer's solution was infused during anaesthesia at a rate of $5 \mathrm{ml} / \mathrm{kg} / \mathrm{h}$ to prevent contrast medium induced acute kidney injury (CI-AKI) $[15,16]$.

Dose reports were stored for each acquired CT image series. Images have been evaluated using a certified software 64 bit OsirixMED ${ }^{\circ}$ (Aycan Medical System, LLC) and the identification of the uretero-vesicular junction was assessed for each patient in transverse slices, dorsal and longitudinal reconstructions (Volume Rendering, Multiplanar Reformation and Maximum Intensity Projection).

The scans of interest for the evaluation of the ureteral junction (conventional unenhanced and enhanced series, low exposure axial series and late enhanced series with bolus tracking technique) were selected from the Dose Report of each dog. The Dose Length Product (DLP) values for each scan were added together in order to obtain an estimated total DLP value for each dog. Using the formulas suggested in the AAPM 96 report [17] the effective dose for each scan was calculated by multiplying the DLP by the corrected conversion factor. In particular conversion factors of different human sizes (0 year old, 1 year old, 5 years old, 10 years old and adult) based on patient weight were used (Table 2).

\section{Results}

Ten dogs of different breeds (4 intact females, 3 neutered females, 3 intact male) were enrolled. Body weight varied from 2,8 to $32 \mathrm{~kg}$ (mean 16,83 $\mathrm{kg}$ ) and the mean age was 10,2 years, ranging from 8 to 14 years. All dogs had no history or signs of urinary tract illness, based on blood tests and pre-anaesthetic clinical evaluation.

The uretero-vesicular junction, was easily identified in all (100 \%) patients in the late bolus tracking scans, and clearly visualized when the MIP post-processing technique was adopted (Figs. 2 and 3).

Based on Dose reports the volumetric computed tomography dose index (CTDI vol) values, both partial and total dose length product (DLP) values and effective doses were estimated (Table 2). The effective dose range was quite wide due to different patient weights. In particular the average effective dose for the pelvic region acquisition was $20.1 \pm 11.9 \mathrm{mSv}$ (range 3.1-45.6 mSv) and average effective dose, considering the whole protocol, was $74.8 \pm 25.6 \mathrm{mSv}$ (range $37.5-138 \mathrm{mSv}$ ).

\section{Discussion}

The bolus tracking technique is a tomographic modality of bolus contrast synchronization widely applied in human medicine, mainly for the examination of the cardiocirculatory system and perfusion index of neoplasms, especially located in the liver $[18,19]$. Bolus tracking technique allows a real time monitoring of the contrast bolus by selecting a region of interest commonly positioned in the lumen of a vessel [18]. To the author's 
Table 2 CTDI Vol, Partial and Total DLP, DPL Refined with Human Pelvis Weighing Factor

\begin{tabular}{|c|c|c|c|c|c|c|}
\hline Breed & $\begin{array}{l}\text { Weight } \\
(\mathrm{kg}) \\
\text { (reference } \\
\text { man) }\end{array}$ & Scan & $\begin{array}{l}\text { CTDI } \\
\text { vol } \\
\text { (mGy) }\end{array}$ & $\begin{array}{l}\text { DLP } \\
(\mathrm{mGy}-\mathrm{cm})\end{array}$ & $\begin{array}{l}\text { Human } \\
\text { pelvis } \\
\text { weighing } \\
\text { factor }\end{array}$ & $\begin{array}{l}\text { Effective } \\
\text { dose } \\
(\mathrm{mSv})\end{array}$ \\
\hline \multirow[t]{5}{*}{ Akita } & 30 (10 yo) & $\mathrm{CU}$ & 19.93 & 2002,77 & 0,015 & 30,0 \\
\hline & & CE & 19.93 & 2002,77 & & 30,0 \\
\hline & & SA & 29.17 & 29,17 & & 0,4 \\
\hline & & LEBT & 19.93 & 906,5 & & 13,6 \\
\hline & & & & 4941,21 & & 74,1 \\
\hline \multirow[t]{5}{*}{ Pinscher } & 6 (1 yo) & $\mathrm{CU}$ & 22.30 & 889,9 & 0,03 & 26,7 \\
\hline & & CE & 22.30 & 889,9 & & 26,7 \\
\hline & & SA & 66.67 & 66,67 & & 2,0 \\
\hline & & LEBT & 22.30 & 103,8 & & 3,1 \\
\hline & & & & 1950,27 & & 58,5 \\
\hline \multirow[t]{5}{*}{ Mixed breed } & 5.5 (1 yо) & $\mathrm{CU}$ & 18.94 & 894,31 & 0,03 & 26,8 \\
\hline & & CE & 18.94 & 894,31 & & 26,8 \\
\hline & & SA & 45.84 & 45,84 & & 1,4 \\
\hline & & LEBT & 18.94 & 894,31 & & 26,8 \\
\hline & & & & 2728,77 & & 81,9 \\
\hline \multirow[t]{5}{*}{ Irish Setter } & 26 (10 yo) & $\mathrm{CU}$ & 19.93 & 1305,14 & 0,015 & 19,6 \\
\hline & & CE & 19.93 & 709,67 & & 10,6 \\
\hline & & SA & 29.17 & 29,17 & & 0,4 \\
\hline & & LEBT & 19.93 & 458,02 & & 6,9 \\
\hline & & & & 2502 & & 37,5 \\
\hline \multirow[t]{5}{*}{ Labrador Retriever } & 31 (10 yo) & CU & 21.71 & 2200,23 & 0,015 & 33,0 \\
\hline & & CE & 21.7 & 2200,23 & & 33,0 \\
\hline & & SA & 33.34 & 33,34 & & 0,5 \\
\hline & & LEBT & 19.93 & 874,11 & & 13,1 \\
\hline & & & & 5307,91 & & 79,6 \\
\hline \multirow[t]{5}{*}{ Pinscher } & 5 (1 yо) & $\mathrm{CU}$ & 19.93 & 799,36 & 0,03 & 24,0 \\
\hline & & CE & 19.93 & 799,36 & & 24,0 \\
\hline & & SA & 12.50 & 12,5 & & 0,4 \\
\hline & & LEBT & 19.93 & 799,36 & & 24,0 \\
\hline & & & & 2410,58 & & 72,3 \\
\hline \multirow[t]{6}{*}{ Mixed breed } & 30 (10 yo) & $C U$ & 19.93 & 1397,33 & 0,015 & 21,0 \\
\hline & & CE & 19.93 & 1397,33 & & 21,0 \\
\hline & & SA & 12.50 & 12,5 & & 0,2 \\
\hline & & SA & 12.50 & 29,17 & & 0,4 \\
\hline & & LEBT & 19.93 & 1397,33 & & 21,0 \\
\hline & & & & 4233,66 & & 63,5 \\
\hline \multirow[t]{5}{*}{ Pinscher } & 2,8 (0 yo) & $\mathrm{CU}$ & 17.94 & 930,21 & 0,049 & 45,6 \\
\hline & & CE & 17.94 & 930,21 & & 45,6 \\
\hline & & SA & 25.00 & 25 & & 1,2 \\
\hline & & LEBT & 17.94 & 930,21 & & 45,6 \\
\hline & & & & 2816,63 & & 138,0 \\
\hline Pug & 11 (5 yo) & $\mathrm{CU}$ & 19.93 & 1193,02 & 0,02 & 23,9 \\
\hline
\end{tabular}


Table 2 CTDI Vol, Partial and Total DLP, DPL Refined with Human Pelvis Weighing Factor (Continued)

\begin{tabular}{|c|c|c|c|c|c|c|}
\hline & & CE & 19.93 & 1193,02 & & 23,9 \\
\hline & & SA & 12.50 & 12,5 & & 0,3 \\
\hline & & LEBT & 19.93 & 1193,02 & & 23,9 \\
\hline & & & & 3591,56 & & 71,8 \\
\hline \multirow[t]{6}{*}{ English Setter } & 20 (5 yo) & $\mathrm{CU}$ & 19.93 & 1153,16 & 0,02 & 23,1 \\
\hline & & CE & 19.93 & 1153,16 & & 23,1 \\
\hline & & SA & 54.17 & 54,17 & & 1,1 \\
\hline & & SA & 25.00 & 25 & & 0,5 \\
\hline & & LEBT & 19.93 & 1153,16 & & 23,1 \\
\hline & & & & 3538,65 & & 70,8 \\
\hline
\end{tabular}

$N F$ neutered female, IM intact male, IF intact female, $C U$ conventional unenhanced, CE conventional enhanced, $S A$ single axial, $L E B T$ late enhanced with bolus tracking technique
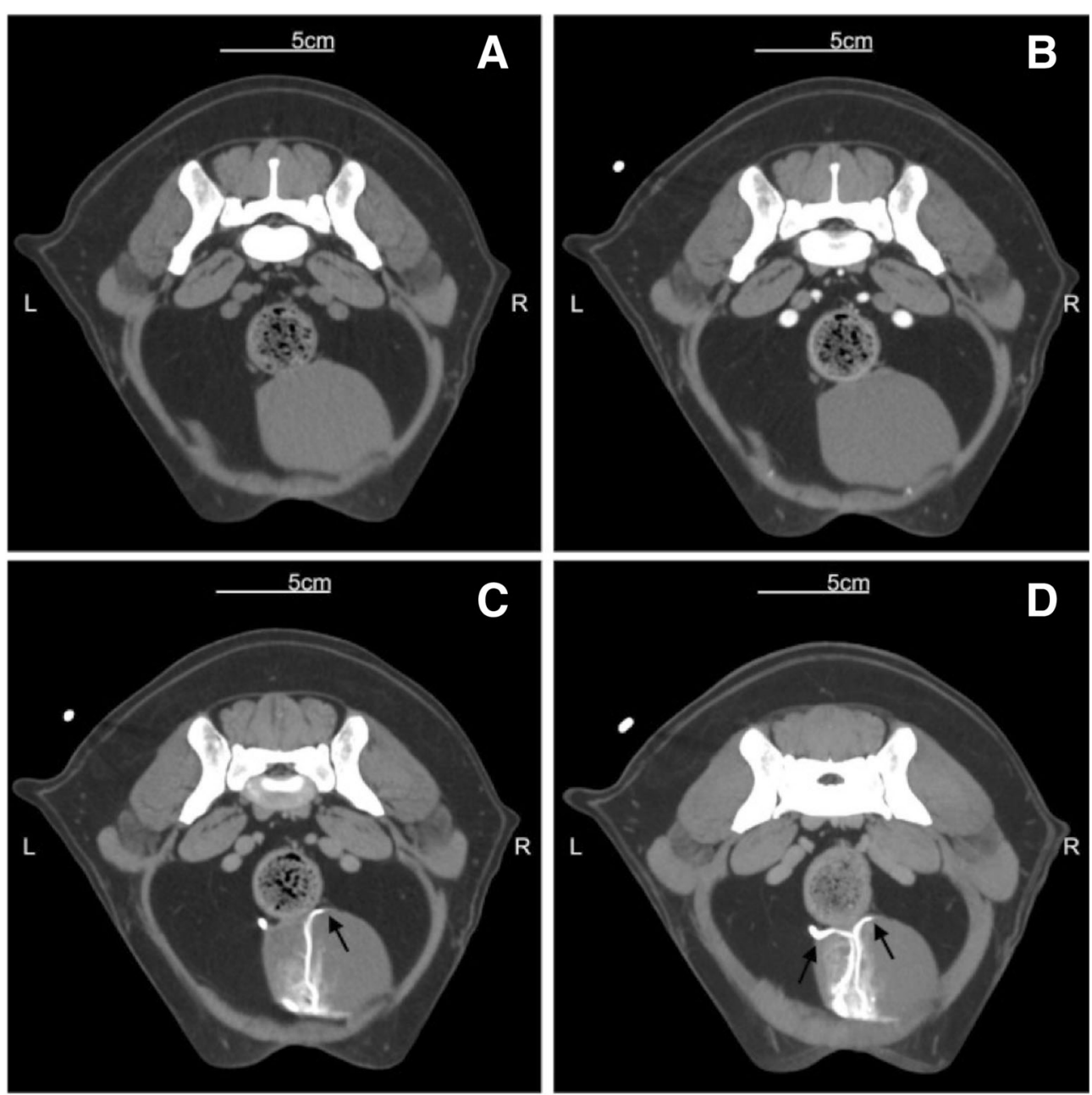

Fig. 2 Transverse images at the level of the uretero-vesicular junction. Gradual distribution of the contrast media: unhenhanced conventional scan (a), vascluar distribution in the enhanced conventional scan (b), late post-contrast enhanced series with bolus tracking technique (c), reconstructed by MIP (d). Black arrows indicate the uretero-vesicular junction 


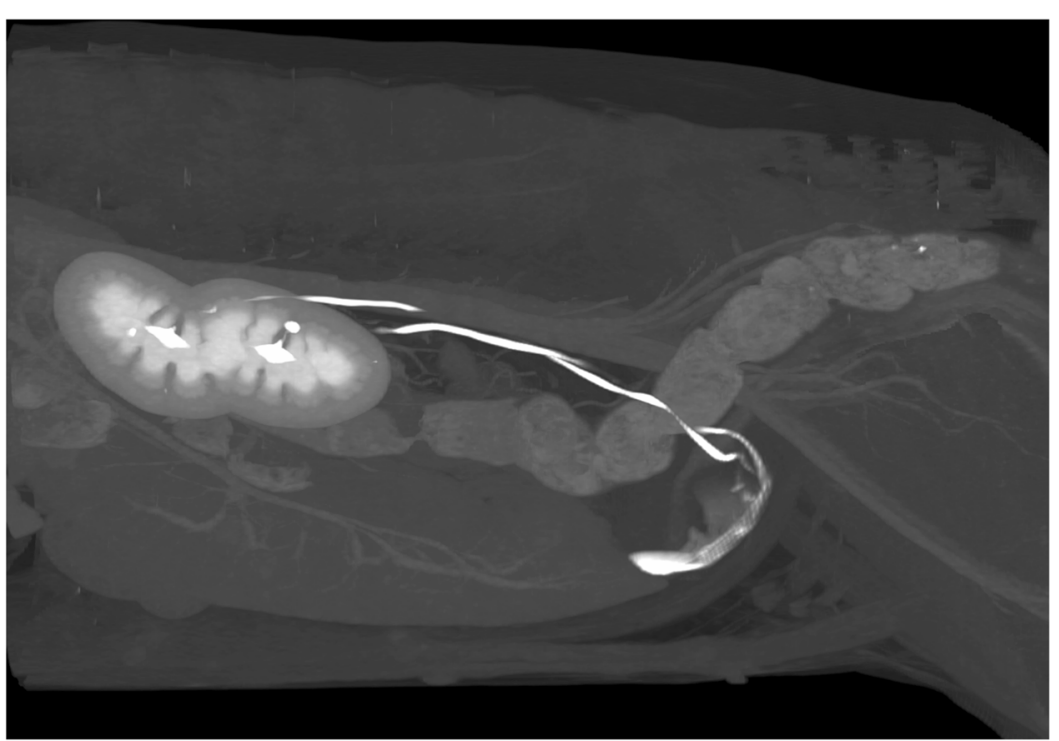

Fig. 3 Post-contrast sagittal 3D MIP of the abdomen showing the enhanced uretero-vesicular junctions and the ureteral washout

knowledge, the visualization of the uretero-vesicular junction by placing a ROI into the ureteral lumen has never been reported before.

The need to apply this dynamic scan technique to the urinary tract has been inspired by the everyday time-consuming radiographic and tomographic examination of the excretory apparatus in veterinary patients, as in case of CTEU or combined intravenous pyelogram (IVP) and CT. This kind of studies can be strongly influenced by many variables, such as patient dimensions, body weight, total blood volume, heart rate and contrast medium [20]. These parameters, highly variable in physiological conditions, may differ even more when pathological conditions occur, such as ureteral ectopia, and when anaesthetic drugs are administered [21, 22].

In this study the bolus tracking technique has been applied in dogs with no signs of urinary tract illness, in order to verify its application on this apparatus in normal conditions. The uretero-vesicular junction was recognisable as a hook-shaped structure corresponding to the medial deflection of the distal ureters as they insert in the bladder wall [23]. It was easily identified in all patients in the late bolus tracking scans and better visualized when the MIP post-processing technique was used. Some authors indicated coronal views for humans as the best reconstructions to allow a successful visualization of the distal ureters without MIP, since this technique is reported to reduce the density values of the enhanced ureters in humans [3]. Our results are partially in agreement with those previously reported: we observed a slight enhancement reduction using MIP but this did not influence the ability of the radiologist in the thorough visualization of the uretero-vesicular junction. This could probably lead back to the anatomical difference of the abdominal anatomical shape between humans and animals, more compressed dorso-ventrally in non-obese people than in animals, where it usually develops in a circular transverse shape. For this reasons it could be easier to obtain a coronal reconstruction of the caudal abdomen in humans, for a correct estimation of the uretero-vesicular junction because in the same plane coronal images can provide the appearance of both kidneys and ureters.

The application of the bolus tracking technique by selecting a ROI in the ureteral lumen allows bypassing most of the above-quoted issues, clearly visualizing the uretero-vesicular junction, in normal conditions. Moreover, our study shows that the bolus tracking technique can be successfully applied despite different anaesthetic protocols as the uretero-vesicular junction is clearly visualized. Further studies will be required in the future to evaluate the applicability of the bolus tracking technique in patients with urinary tract illness and after the administration of other pre-anesthetic and anesthetic drugs.

An additional pressing problem, as far as the radiographic and tomographic exam of the pelvis is concerned, could be patient exposure $[4,5]$. X-rays are accountable for both deterministic and stochastic effects [24-26] and precise thresholds are available for humans [25]. Many authors [4, 5, 9] evaluated human patients exposure during CT pelvic exams, but no evaluation has ever been proposed for veterinary patients: this was the second aim of this study. Patients exposure was estimated choosing the appropriate scan series in the dose report of each patient, and later refining them with the application of human pelvis weighing factors (Table 2). The estimation of the effective doses to pelvis turned 
out to be quite elevated if compared to human reported values [2-8] but it must be taken into account that these values could be affected by the weighting factors related to human references and that the acquisition protocol parameters are not optimized for dose reduction purposes. However, the effective doses we estimated were in any case well away from deterministic human damage thresholds and never got closed to stochastic damage thresholds either. Furthermore, the aim of this study was also to demonstrate that the use of bolus tracking could decrease patient exposure. Actually, the ability of this technique to identify the optimal time delay for ureters visualization, allows the reduction of patient dose by avoiding useless exposures due to repeated acquisitions.

\section{Conclusions}

We consider the bolus tracking technique as a useful tool to evaluate the distal portion of the ureters and the uretero-vesicular junction in dogs without urinary tract illness. This modality can enhance the visualization of this region, possibly limiting the effective dose the patients receive from conventional uro-tomographic studies of the pelvis. Even if radio-exposure could be a minor concern in veterinary patients, when compared to humans, we would like to recommend a stressful attention to radio-exposure for this type of studies, not only for the anatomical region exposed, but also for the high prevalence of paediatric veterinary patients admitted for this exams [26]. Future perspectives will be oriented to the application of ureteral bolus tracking technique in pathological conditions, taking into consideration the reduction of the effective doses for veterinary patients.

\section{Declarations}

The study have been performed under written informed consent of the owner in each case, according to Animal ethics national/EU laws.

\section{Abbreviations \\ CT: computed tomography; CTDI vol: volumetric computed tomography dose index; CTEU: Computed Tomography Excretory Urography; DLP: Dose Length Product; IVP: intravenous pyelogram; MIP: Maximum Intensity Projection; ROI: region of interest.}

\section{Competing interests}

The authors declare they have no competing interests.

\section{Authors' contributions}

ML, MDG, DZ designed the research. ML, MEA, DDZ, DZ carried out the CT examinations and dose records. GR and VR performed the anaesthesia. ML and MEA drafted the work. CP and MEA carried out the dose assessment. MDG and DZ gave final approval of the version to be published. All authors finally read and approved the manuscript.

\section{Author details}

${ }^{1}$ Department of Veterinary Medicine (DIMEVET), Università degli Studi di Milano, Ospedale Didattico Universitario Az. Polo Veterinario di Lodi, Via dell'Università 6, 26900 Lodi, LO, Italy. ${ }^{2}$ Medical Physics Unit,

S.Orsola-Malpighi University Hospital, Bologna, Italy.
Received: 7 September 2015 Accepted: 22 March 2016

Published online: 29 March 2016

\section{References}

1. Berrocal T, Pereira PL, Arjonilla A, Gutiérrez J. Anomalies of the Distal Ureter, Bladder, and Urethra in Children: Embryologic, Radiologic, and Pathologic Features. RSNA 2002; DOI: http://dx.doi.org/10.1148/radiographics.22.5. g02se101139.

2. Caoili EM, Cohan RH, Korobkin M, Platt JF, Francis IR, Faerber GJ, Montie JE, Ellis $\mathrm{JH}$. Urinary tract abnormalities: initial experience with multi-detector row CT urography. Radiology. 2002;222(2):353-60.

3. McTavish JD, Jinzaki M, Zou KH, Nawfel RD, Silverman SG. Multi-detector row $C T$ urography: comparison of strategies for depicting the normal urinary collecting system. Radiology. 2002;225:783-90.

4. Nawfel RD, Judy PF, Schleipman AR, Silverman SG. Patient radiation dose at CT urography and conventional urography. Radiology. 2004;232(1):126-32.

5. Villat J, Cowan NC. CT urography: is the increased patient radiation dose justified? Eur Radiol. 2004;14:T5.

6. Nolte-Ernsting C, Cowan N. Understanding multislice $C T$ urography techniques: Many roads lead to Rome. Eur Radiol. 2006;16(12):2670-86. Epub 2006 Sep 5.

7. Dillman JR, Caoili EM, Cohan RH, Ellis JH, Francis IR, Nan B, Zhang Y. Comparison of urinary tract distension and opacification using single-bolus 3-Phase vs split-bolus 2-phase multidetector row CT urography. J Comput Assist Tomogr. 2007;31(5):750.

8. Kekelidze M, Dwarkasing RS, Dijkshoorn ML, Sikorska K, Verhagen PC, Krestin GP. Kidney and urinary tract imaging: triple-bolus multidetector $C T$ urography as a one-stop shop-protocol design, opacification, and image quality analysis. Radiology. 2010;255(2):508-16

9. Dahlman P, Van der Molen AJ, Magnusson M, Magnusson A. How much dose can be saved in three-phase $C T$ urography? A combination of normaldose corticomedullary phase with low-dose unenhanced and excretory phases. AJR Am J Roentgenol. 2012;199(4):852-60.

10. Mc Nicholas MM, Raptopoulos VD, Schwartz RK, Sheiman RG, Zormpala A, Prassopoulos PK, Ernst RD, Pearlman JD. Excretory phase CT urography for opacification of the urinary collecting system. AJR Am J Roentgenol. 1998; 170(5):1261-7.

11. Roy C, Jeantroux J, Irani FG, Sauer B, et al. Accuracy of intermediate dose of furosemide injection to improve multidetector row CT urography. Eur J Radiol. 2008;66(2):253-61.

12. Secrest S, Essman S, Nagy J, Schultz L. Effects of furosemide on ureteral diameter and attenuation using computed tomographic excretory urography in normal dogs. Vet Radiol Ultrasound. 2013;54(1):17-24.

13. Schwarz T. Urinary System. In: Schwarz T, Saunders J, editors. Veterinary Computed Tomography. 1st ed. Oxford: Wiley Blackwell; 2011. p. 332-4.

14. Cassel N, Carstens A, Becker P. The comparison of bolus tracking and test bolus techniques for computed tomography thoracic angiography in healthy beagles. J S Afr Vet Assoc. 2013;84(1):E1-9.

15. Seeliger E, Lenhard DC, Persson PB. Contrast media viscosity versus osmolality in kidney injury: lessons from animal studies. Biomed Res Int 2014;2014:358136

16. Carotenuto AM, Borghi L, Paltrinieri S, Giordano A, Moretti P, Di Giancamillo M. Serum biochemical response to contrast media administration in anaesthetised dogs. Vet Rec. 2013;172(4):101.

17. Report of AAPM Task Group 23 of the Diagnostic Imaging Council CT Comitee. The measurement, Reporting and Management of Radiation Dose in CT. January 2008. https://www.aapm.org/pubs/reports/RPT_96.pdf.

18. Silverman PM, Brown B, Wray H, Fox SH, Cooper C, Roberts S, Zeman RK. Optimal contrast enhancement of the liver using helical (spiral) $\mathrm{CT}$ : value of Smart Prep. AJR Am J Roentgenol. 1995;164(5):1169-71.

19. Choi SY, Choi HJ, Lee KJ, Lee YW. Establishment of optimal scan delay for multi-phase computed tomography using bolus-tracking technique in canine pancreas. J Vet Med Sci. 2015;6.

20. Feeney DA, Thrall DE, Barber DL, Culver DH, Lewis RE. Normal canine excretory urogram: effects of dose, time, and individual dog variation. Am J Vet Res. 1979;40(11):1596-604.

21. Grimm JB, Grimm KA, Kneller SK, Tranquilli WJ, Crochik SS, Bischoff MG, Podolski $\mathrm{J}$. The effect of a combination of medetomidine-butorphanol and medetomidine, butorphanol, atropine on glomerular filtration rate in dogs. Vet Radiol Ultrasound. 2001;42(5):458-62. 
22. Danuser H, Weiss R, Abel D, Walter B, Scholtysik G, Mettler D, Studer UE. Systemic and topical drug administration in the pig ureter: effect of phosphodiesterase inhibitors alpha1, beta and beta2-adrenergic receptor agonists and antagonists on the frequency and amplitude of ureteral contractions. J Urol. 2001;166(2):714-20.

23. Rozear $\mathrm{L}$, Tidwell AS. Evaluation of the ureter and uretero vesicular junction using helical computed tomographic excretory urography in healthy dogs. Vet Radiol Ultrasound. 2003;44(2):155-64.

24. Colagrande S, Origgi D, Zatelli G, Giovagnoni A, Salerno S. CT exposure in adult and paediatric patients: a review of the mechanisms of damage, relative dose and consequent possible risks. Radiol Med. 2014;119(10):803-10.

25. Hendee WR, O'Connor MK. Radiation risks of medical imaging: separating fact from fantasy. Radiology. 2012;264(2):312-21.

26. Bakhmutsky MV, Joiner MC, Jones TB, Tucker JD. Differences in cytogenetic sensitivity to ionizing radiation in newborns and adults. Radiat Res. 2014; 181(6):605-16.

Submit your next manuscript to BioMed Central and we will help you at every step:

- We accept pre-submission inquiries

- Our selector tool helps you to find the most relevant journal

- We provide round the clock customer support

- Convenient online submission

- Thorough peer review

- Inclusion in PubMed and all major indexing services

- Maximum visibility for your research

Submit your manuscript at www.biomedcentral.com/submit
Biomed Central 